\title{
Postprandial Changes in Plasma Free Amino Acid Concentrations of Rainbow Trout Fed Diets Containing Different Protein Sources*1
}

\author{
Takeshi Yamamoto, ${ }^{* 2}$ Tatsuya Unuma, ${ }^{* 2}$ and Toshio Akiyama ${ }^{* 2}$ \\ ${ }^{*}$ Nutrition Section, Inland Station, National Research Institute of \\ Aquaculture, Tamaki, Mie 519-0423, Japan
}

(Received November 27, 1997)

\begin{abstract}
Postprandial changes in plasma free amino acid concentrations and nitrogen contents of the gastrointestinal digesta of rainbow trout Oncorhynchus mykiss fed different protein sources were examined. Three experimental diets containing either white fish meal (FM), defatted soybean meal (SBM) or malt protein flour (MPF), were fed to triplicate groups (initial mean weight; $63 \mathrm{~g}$ ) for two weeks at $15^{\circ} \mathrm{C}$. After 48 hours of fasting, the fish were fed again the respective diets to satiation. Blood samples were taken at $3,6,9,12,15,18,21,24$, and 48 hours after the last feeding.

Plasma concentrations of individual amino acids reached peak levels at $12 \pm 3$ hours post-feeding in the FM group, and at $21 \pm 3$ hours in the SBM and MPF groups. Evacuation of gastric digesta was faster in the FM and SBM groups than the MPF group. However, the $0.9 \% \mathrm{NaCl}$ insoluble nitrogen levels (\%) in the gastric digesta of the SBM and MPF groups seemed relatively stable until 21 hours compared with the decreasing trend observed in the FM group. The insoluble nitrogen contents $(\mathrm{mg} / 100 \mathrm{~g}$ BW) in the intestinal digesta were highest in the MPF group, intermediate in the FM group, and unexpectedly lowest in the SBM group throughout the sampling periods.

These findings suggest that peak levels of plasma free amino acids in the SBM and MPF groups occurred later than the FM group due in part to different protein digestive processes in the gastrointestinal tract.
\end{abstract}

Key words: alternative protein sources, fish meal, gastrointestinal digesta, malt protein flour, Oncorhynchus mykiss, soybean meal, plasma free amino acid, postprandial change

Postprandial changes in plasma free amino acid concentrations of fish fed different kinds of diet have been compared in several papers. ${ }^{1-11)}$ Some of these reports focused on the difference between diets containing a high proportion of crystalline amino acids and diets containing intact proteins such as casein. ${ }^{1-4,6,7,11)}$ These studies have shown in principle that peak levels of plasma free amino acid concentrations occur much earlier in fish fed amino acid diets than intact protein diets. ${ }^{2-4,7,11)}$ It is also recognized that a diet containing intact protein(s) supplemented with crystalline amino acids sometimes results in inferior growth and feed performance compared to an ideal intact protein diet. $^{12-17)}$ Thus the faster absorption of crystalline amino acids and their subsequent catabolism is considered to be one of the causes of inferior growth and feed performance of the fish. ${ }^{3,7,16,17)}$

In contrast, few reports have compared the postprandial plasma (or serum) free amino acid concentrations between diets from the viewpoint of practical feed formulation. ${ }^{5,8-10)}$ In fish feed, multiple protein ingredients such as fish meal and soybean meal are usually incorporated, and sometimes crystalline amino acids are further supplemented to balance the amino acid profile of the feed. ${ }^{14-19}$ To achieve an efficient utilization of amino acids from these nitrogenous ingredients in the feed, free amino acids derived from each of these ingredients should be present simultaneously in plasma with a balanced composition as has been suggested by Murai et al. ${ }^{4}$ in carp Cyprinus carpio. Therefore, it is important to elucidate postprandial changes of plasma free amino acid concentrations of fish fed different practical protein sources. However, only Shimeno et al. examined in yellowtail Seriola quinqueradiata the effects of including defatted soybean meal (SBM) into the fish meal based moist pellet, ${ }^{10)}$ and of force-feeding brown fish meal and SBM. ${ }^{97}$ More examinations are necessary to clarify the postprandial plasma free amino acid changes of fish fed various protein sources.

Close relationship between postprandial changes of plasma free amino acid levels and digestive process of diets has been suggested..$^{3,8,10)}$ Shimeno et al.$^{8,10)}$ observed that yellowtail fed raw fish showed clear peaks of serum free amino acid concentrations at two to four hours post-feeding, while fish fed single moist pellets did not show distinct peaks. They found that the fish meal proteins in the moist pellets were evacuated from stomach less digested than the proteins of raw fish. Yamada et al..$^{3)}$ also observed that casein was evacuated from stomach more slowly than amino acid mixture in rainbow trout Oncorhynchus mykiss. Accordingly, postprandial plasma free amino acid levels for protein ingredients should be examined in relation to the digestive process of the proteins.

To clearly explain the effect of different kinds of practi-

\footnotetext{
${ }^{*}$ This study was presented in part at the Meeting of the Japanese Society of Fisheries Science, Higashi-Hiroshima, September, 1997.
} 
cal protein sources on the plasma free amino acid concentrations of fish, we first examined the postprandial plasma free amino acid concentrations of rainbow trout fed ad libitum dry pellets containing either white fish meal (FM), SBM or malt protein flour (MPF) in this study. Since we found that peak levels of plasma free amino acids in the SBM and MPF groups occurred approximately 9 hours later than the FM group, we further examined nitrogen content changes in the gastric and intestinal digesta of the fish to make clear the digestive process of the proteins.

\section{Materials and Methods}

\section{Experimental Diets}

The formulation, and proximate and amino acid compositions, of the experimental diets are shown in Table 1. Three diets each containing FM (Alaska pollock meal, produced by JSC Oceanrybflot, Russia), SBM (Marubeni Shiryo Co. Ltd., Japan) or MPF (Kirin Brewery Co. Ltd., Japan), as the sole protein source, were formulated to provide a diet of approximately $35 \%$ crude protein. Crude fat levels of the diets were adjusted to approximately $15 \%$ by addition of pollock visceral oil (Riken Vitamin Co. Ltd., Japan) and soybean oil (Wako Pure Chemical Industries Ltd., Japan). All these ingredients were thoroughly mixed, moistened, and pelleted without steam, using a Laboratory Pellet Mill CL-2 (California Pellet Mill Co., USA). The resulting pellets (approximately $4.5 \mathrm{~mm}$ diam. $\times 7.2 \mathrm{~mm}$ ) were dried at $60^{\circ} \mathrm{C}$ for five hours, and then stored at $-20^{\circ} \mathrm{C}$ until fed to the fish.

\section{Fish and Feeding Procedures}

Fingerling rainbow trout were transferred from the Shiga Prefectural Samegai Trout Farm to the Inland Station of the National Research Institute of Aquaculture. The fish were reared with a commercial trout feed (Nippon Formula Feed Mfg. Co. Ltd., Japan) supplemented with $5 \%$ $(w / w)$ pollock visceral oil for four months at $15^{\circ} \mathrm{C}$. Two hundred and seventy fish with a similar size $(63 \pm 6.9 \mathrm{~g})$ were then selected and divided into nine groups ( 30 fish per group). Each of the nine groups was stocked into a round tank (holding about $120 \mathrm{l}$ of water), and well water $\left(15 \pm 0.4^{\circ} \mathrm{C}\right)$ was supplied at a flow rate of $4 l$ per min. The fish were fed the commercial trout feed for the initial two weeks of acclimation to the rearing conditions. Then the three experimental diets were each fed to the triplicate groups to satiation twice per day for the following two weeks. After 48 hours of fasting, the fish were then fed once again to satiation, and blood samples were taken. In all treatments, amounts of diets consumed at the last feeding were approximately the same.

\section{Sampling Procedures}

Four fish were sampled from one of the three tanks for each dietary treatment at three hour intervals from three to 24 hours, and at 48 hours, after the last feeding. To minimize stress from disturbance, fish were sampled from the first tank at 3,12 , and 21 hours, from the second tank at 6,15 , and 24 hours, and from the third tank at 9,18 , and 48 hours post-feeding. The sampled fish were anesthetized with $0.01 \%$ ethyl 3-methylaminobenzoate methanesulfonic acid. A blood sample was immediately
Table 1. Ingredients and proximate and amino acid compositions of the experimental diets

\begin{tabular}{|c|c|c|c|}
\hline Diet $^{* 1}$ & FM & SBM & MPF \\
\hline \multicolumn{4}{|l|}{ Ingredients (\%) } \\
\hline White fish meal & 51.4 & - & - \\
\hline Soybean meal & - & 72.6 & - \\
\hline Malt protein flour & - & - & 67.2 \\
\hline Pollock visceral oil & 3.1 & 6.0 & 6.0 \\
\hline Soybean oil & 9.0 & 8.2 & 0.7 \\
\hline$\alpha$-Starch & 15.0 & 1.7 & 14.6 \\
\hline Dextrin & 5.0 & 5.0 & 5.0 \\
\hline Cellulose & 10.0 & - & - \\
\hline Vitamin $\operatorname{mix}^{*_{2}}$ & 1.5 & & \\
\hline Mineral mix ${ }^{*_{3}}$ & $4.0\}$ & 6.5 & 6.5 \\
\hline Na-alginate & 1.0 & & \\
\hline \multicolumn{4}{|l|}{ Proximate composition ( $\%$ dry matter) } \\
\hline Crude protein $(\mathrm{N} \times 6.25)$ & 35.4 & 34.9 & 35.6 \\
\hline Crude fat $(\%)$ & 15.9 & 16.2 & 16.5 \\
\hline Crude ash $(\%)$ & 14.2 & 7.5 & 4.0 \\
\hline Gross energy $(\mathrm{kJ} / \mathrm{g})^{*_{4}}$ & 20.5 & 21.8 & 23.2 \\
\hline \multicolumn{4}{|l|}{ Amino acid composition ( $\mathrm{g} / 100 /$ protein) } \\
\hline Arginine & 6.90 & 7.75 & 5.38 \\
\hline Histidine & 2.44 & 2.78 & 2.30 \\
\hline Isoleucine & 4.41 & 4.62 & 4.35 \\
\hline Leucine & 8.00 & 8.06 & 9.42 \\
\hline Lysine & 8.43 & 6.63 & 3.34 \\
\hline Methionine & 3.37 & 1.35 & 2.12 \\
\hline Cystine & 1.12 & 1.62 & 2.42 \\
\hline Phenylalanine & 4.16 & 5.41 & 6.36 \\
\hline Tyrosine & 3.67 & 3.59 & 3.93 \\
\hline Threonine & 4.30 & 3.86 & 3.60 \\
\hline Tryptophan & 1.11 & 0.29 & 0.41 \\
\hline Valine & 4.88 & 4.57 & 5.15 \\
\hline Alanine & 6.28 & 4.55 & 4.96 \\
\hline Aspartic acid & 10.20 & 11.14 & 6.27 \\
\hline Glutamic acid & 14.29 & 19.09 & 22.27 \\
\hline Glycine & 6.84 & 4.37 & 3.40 \\
\hline Proline & 4.40 & 5.16 & 10.25 \\
\hline Serine & 4.85 & 4.85 & 4.07 \\
\hline Hardness of diet $(\mathrm{kg} \cdot \mathrm{f})^{* 5}$ & 0.95 & 0.82 & 4.53 \\
\hline \multicolumn{4}{|c|}{ Nitrogen content of each fraction (\% to total nitrogen) $)^{*_{6}}$} \\
\hline $0.9 \% \mathrm{NaCl}$ insoluble & 97.6 & 93.5 & 98.6 \\
\hline $\begin{array}{l}0.9 \% \mathrm{NaCl} \text { soluble and perchloric } \\
\text { acid solution insoluble }\end{array}$ & 0.2 & 5.8 & 0.2 \\
\hline Perchloric acid solution soluble & 2.2 & 0.7 & 1.2 \\
\hline
\end{tabular}

*1 FM; white fish meal diet, SBM; soybean meal diet, MPF; malt protein flour diet.

*2 The premix (mg/ $100 \mathrm{~g}$ diet): Thiamin HCl; 5, Riboflavin; 20, Pyridoxine $\mathrm{HCl}$; 5. Choline chloride; 500, Nicotinic acid; 75, Ca-pantothenate; 50, Inositol; 200, Biotin; 0.5, Folic acid; 1.5 , Ascorbic acid; 100, Vitamin $\mathrm{K}_{3} ; 4$, DL- $\alpha-$ tocopherol; 40 , Vitamin $B_{12} ; 0.01$, Vitamin $D_{3} ; 0.005$, Vitamin $A$ acetate; 2000 IU.

*3 The same as in Yamamoto et al. ${ }^{17}$

* Analyzed value using a Bomb Calorimeter CA-4PJ (Shimadzu Co., Japan).

*s Analyzed using a Digital Hardness Tester KTH-20 (Fujiwara Factory Ltd., Japan). The hardness of commercial dry pellets for trout (SP) was determined as $4.15 \mathrm{~kg} \cdot \mathrm{f}$.

${ }^{* 6}$ Fractionation is shown in Fig. 1.

withdrawn from the caudal vain-artery complex with a heparinized syringe fitted with a $23 \mathrm{G}$ needle. The red blood cells were promptly removed by centrifugation at $3,000 \mathrm{rpm}$ for ten minutes, and the supernatant plasma samples were obtained. The plasma samples were then deproteinized by addition of an equal volume of $10 \%$ sulfosalicylic acid, vigorously shaken, and centrifuged at 
$10,000 \mathrm{rpm}$ for ten minutes at $5^{\circ} \mathrm{C}$. The supernatants were taken and stored at $-80^{\circ} \mathrm{C}$ until analysis of the free amino acid composition. The fish from which the blood samples were taken were frozen immediately in liquid nitrogen and stored at $-80^{\circ} \mathrm{C}$ until analysis of the nitrogen contents of the gastric and intestinal digesta.

\section{Analytical Methods}

All proximate and amino acid analyses of the experimental diets were performed according to the same methods as described previously. ${ }^{17)}$ Hardness of the experimental diets was measured using a Kiya Digital Hardness Tester KHT20 (Fujiwara Factory Ltd., Japan), and shown in Table 1. Plasma free amino acid concentrations were individually determined using an automatic amino acid analyzer L8500 (Hitachi Ltd., Japan) with a ninhydrin reagent and lithium buffer system. To understand the digestive processes of dietary proteins more clearly, ${ }^{8-10)}$ the gastric and intestinal contents were separately collected and their nitrogen compounds were separated into three fractions according to the methods described in Fig. 1. Only the samples taken at $3,9,15,21$, and 48 hours post-feeding were analyzed. The contents of the pyloric ceca were not included in the intestinal digesta analysis. The nitrogen content of each fraction was determined by the micro-Kjeldahl method. Since the nitrogen contents in the $0.9 \% \mathrm{NaCl}$ soluble and perchloric acid solution insoluble fraction were found to fluctuate widely and did not show specific postprandial changes in this study, we only discuss the $0.9 \% \mathrm{NaCl}$ insoluble nitrogen (termed insoluble nitrogen), the perchloric acid solution soluble nitrogen (termed soluble nitrogen), and the total nitrogen contents in this paper. The nitrogen contents of the three fractions for the experimental diets are given in Table 1.

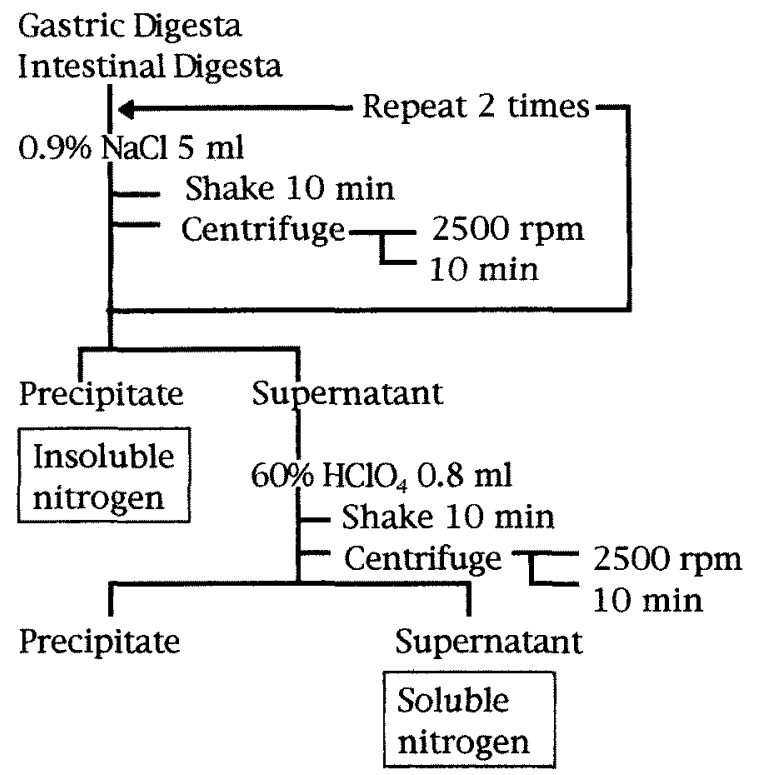

Fig. 1. Fractionation of the gastrointestinal digesta to determine the nitrogen content extracted into each fraction.
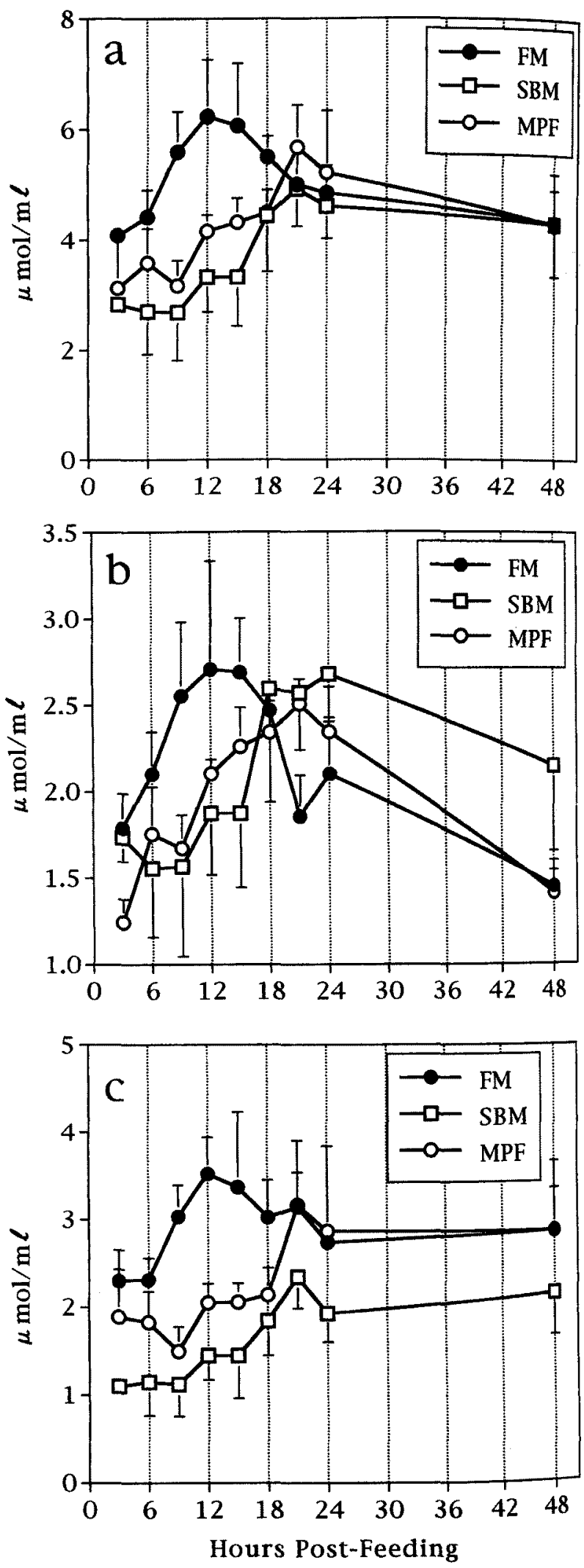

Fig. 2. Total free amino acid (a), total free essential amino acids (b), and total free non-essential amino acids (c) in the plasma of rainbow trout fed diets containing either white fish meal (FM), soybean meal (SBM) or malt protein flour (MPF).

Values are the mean of four fish for each dietary treatment at each sampling time. Vertical lines indicate $1 \mathrm{SD}$. 

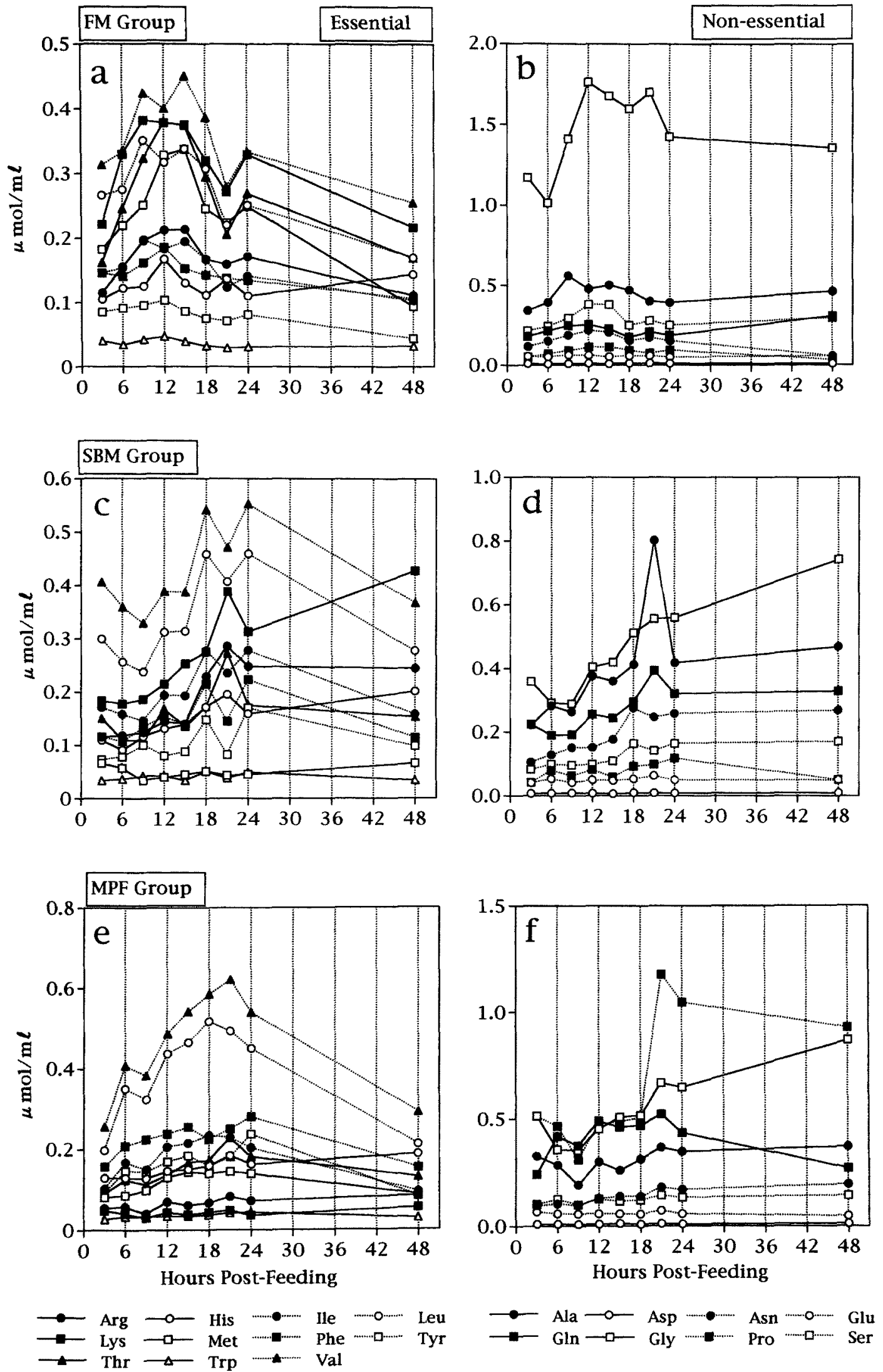

Fig. 3. Individual free amino acids in the plasma of rainbow trout fed diets containing either FM, SBM or MPF.

Essential amino acids and non-essential amino acids of the FM ( $a$ and $b$ ), SBM ( $c$ and $d$ ), and MPF ( $e$ and $f$ ) groups, respectively. Values are the mean of four fish for each dietary treatment at each sampling time. 


\section{Results \\ Postprandial Changes in Plasma Free Amino Acid Concen- trations}

Changes in plasma free amino acid concentrations of rainbow trout after being fed diets containing either FM, SBM or MPF are shown in Fig. 2 and Fig. 3. Peak plasma levels of total amino acids, essential amino acids, and nonessential amino acids in fish fed the FM diet all occurred at 12 hours post-feeding (Fig. 2-a, b, and c). In contrast, the peak levels of these amino acid groups in fish fed the SBM and MPF diets occurred at around 21 hours post-feeding. Peak levels of individual amino acids also occurred close to the peak times of the total amino acids in all three groups ( \pm 3 h, Fig. 3). Due to the decline of isoleucine, leucine, phenylalanine, tyrosine, and valine levels at 21 hours post-feeding in the SBM group, the levels of the total essential amino acids plateaued at 18 to 24 hours (Fig. 2-b). At 48 hours post-feeding, concentrations of most essential amino acids decreased to the levels of 3 hours post-feeding, while most of the non-essential amino acids remained at 24 hours post-feeding levels (Fig. 3). In the FM group, glycine concentrations were markedly high among the non-essential amino acids throughout the sampling periods. On the other hand, drastic elevations of the alanine level of the SBM group and the proline level of the MPF group were observed at 21 hours post-feeding.

\section{Postprandial Changes in Nitrogen Contents of Gastrointes- tinal Digesta}

Changes in the nitrogen contents of digesta in the stomach and intestine are shown in Fig. 4 and Fig. 5, respectively.

Total nitrogen contents in the gastric digesta $(\mathrm{mg} / 100 \mathrm{~g}$ $\mathrm{BW}$ ) of the three groups at 3 hours post-feeding were similar (Fig. 4-a). Thereafter, the nitrogen contents of the FM and SBM groups decreased similarly until 21 hours postfeeding. In contrast, total nitrogen contents of gastric digesta of the MPF group seemed unchanged until 9 hours post-feeding, decreasing thereafter. Since most of the nitrogen in the gastric digesta was found to be insoluble nitrogen, the changes in the insoluble nitrogen contents showed a similar trend to the total nitrogen contents (results not shown). The soluble nitrogen contents $(\mathrm{mg} /$ $100 \mathrm{~g} \mathrm{BW}$ ) of the FM and SBM groups similarly decreased, and were higher than the MPF group during the earlier sampling periods (Fig. 4-b). When the insoluble nitrogen contents were expressed as a percentage of the gastric digesta (Fig. 4-c), however, the values of the SBM and MPF groups were relatively stable until 21 hours post-feeding compared with the decreasing trend of the FM group.

The intestinal digesta per body weight (\% wet weight) of the FM and SBM groups increased up to 9 hours post-feeding, then decreased (Fig. 5-a). On the other hand, the digesta of the MPF group gradually increased up to 21 hours post-feeding. Total nitrogen contents in the intestinal digesta (mg/100 g BW) were, however, highest in the MPF group, intermediate in the FM group, and lowest in the SBM group throughout the sampling periods (Fig. 5-b). The insoluble nitrogen contents $(\mathrm{mg} / 100 \mathrm{~g} \mathrm{BW}$ ) of the MPF group were much higher than the FM group and in-
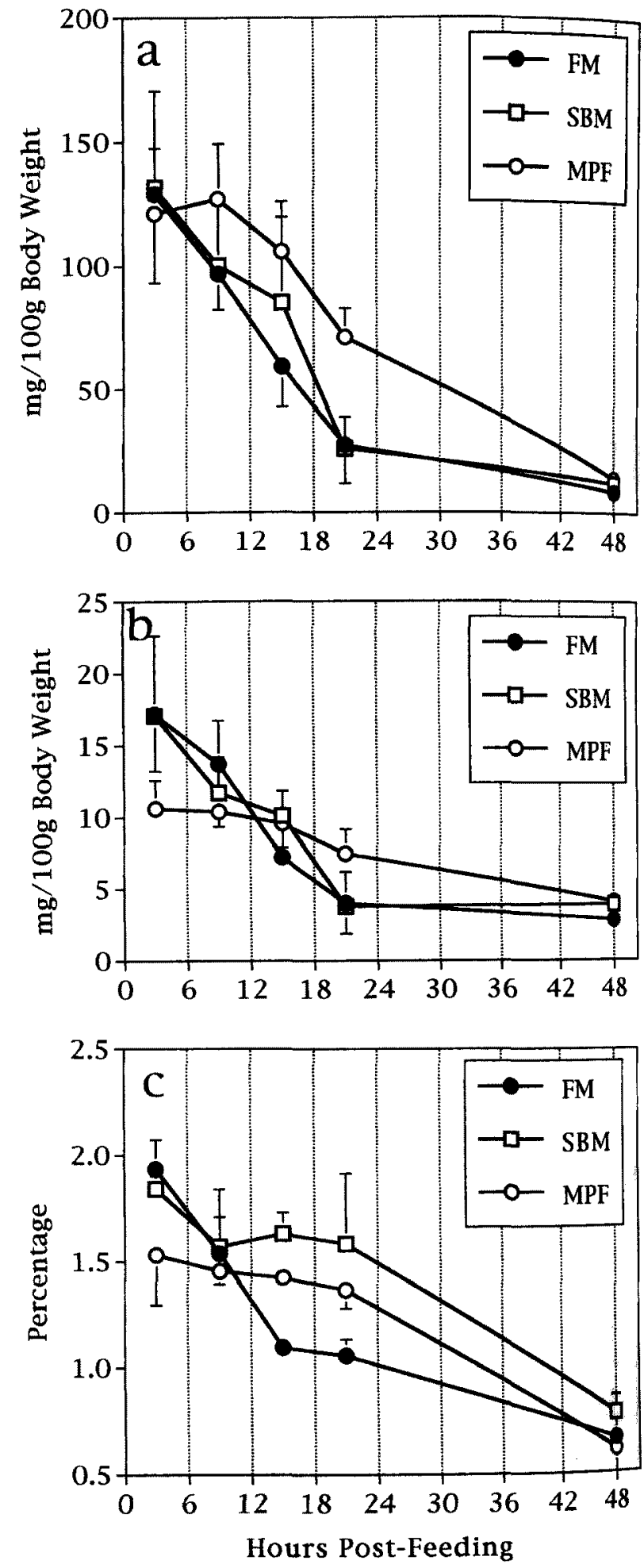

Fig. 4. Nitrogen content in the gastric digesta of rainbow trout fed diets containing either FM, SBM or MPF.

Total nitrogen content (mg/100 g BW) (a), soluble nitrogen content $(\mathrm{mg} / 100 \mathrm{~g} \mathrm{BW})(\mathrm{b})$, and the insoluble nitrogen content to gastric digesta (\%) (c). Values are the mean of four fish for each dietary treatment at each sampling time. Vertical lines indicate $I S D$.

creased until 21 hours post-feeding (Fig. 5-c). The insoluble nitrogen of the SBM group also tended to increase up to 15 hours post-feeding, but the nitrogen contents were 

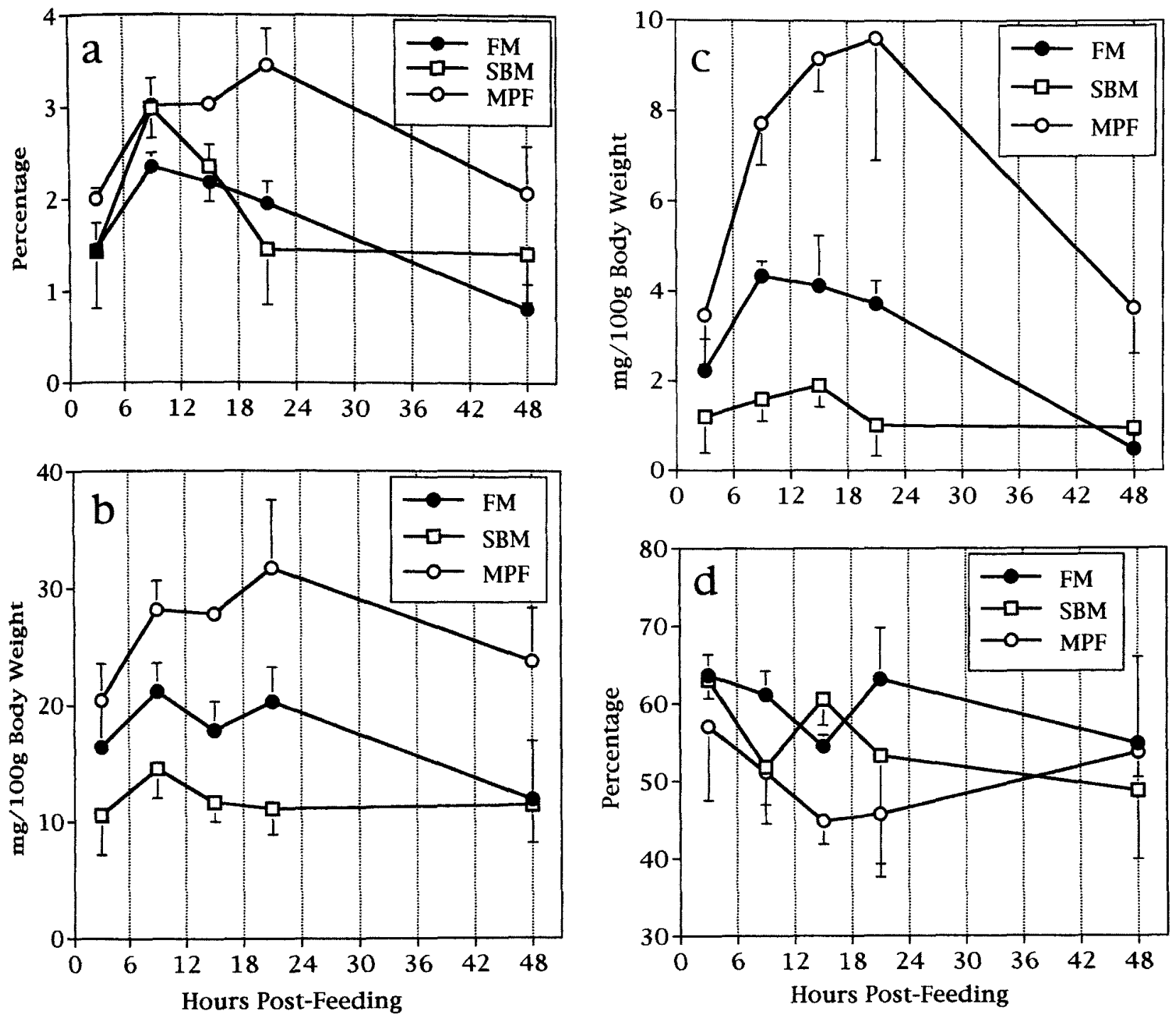

Fig. 5. Nitrogen content in the intestinal digesta of rainbow trout fed diets containing either FM, SBM or MPF.

Intestinal digesta (\% wet weight/ BW) (a), total nitrogen content (mg/100 g BW) (b), insoluble nitrogen content (mg/ $100 \mathrm{~g} \mathrm{BW)} \mathrm{(c),} \mathrm{and} \mathrm{the}$ soluble nitrogen to total nitrogen ratio $(\%)(d)$. Values are the mean of four fish for each dietary treatment at each sampling time. Vertical lines indicate 1 SD.

considerably lower than the other groups. Since the total nitrogen contents of the intestinal digesta of the MPF group were markedly higher than the FM group, the soluble nitrogen contents expressed per body weight were always higher in the MPF group than the FM group (results not shown). However, when the values were expressed as a ratio $(\%)$ of soluble nitrogen to total nitrogen, the values for the MPF group were always lower than the FM group (Fig. 5-d).

\section{Discussion}

In this study we showed clearly that the plasma free amino acid concentrations of rainbow trout fed diets containing either SBM or MPF reached peak levels approximately 9 hours later (at 21 hours post-feeding) than fish fed the diet containing FM (at 12 hours post-feeding). Shimeno et al. found no apparent difference in the timing of serum free amino acid peak concentrations between yellowtail fed moist pellets with or without SBM, ${ }^{10}$ ) or between yellowtail force-fed brown fish meal and SBM. ${ }^{9)}$ These contradictions may in part result from the differences in fish species and the physical properties of the diets, i.e., the yellowtail digested the moist pellets more rapidly ${ }^{8-10}$ than the rainbow trout fed the dry pellets in this study. To make clear the cause of observed time lag of the plasma free amino acid changes among the protein sources in this study, we investigated the digestive process of the proteins in the gastrointestinal tract.

Yamada et al. ${ }^{3)}$ showed that slower evacuation of casein from the stomach was related to the delayed increase of plasma free amino acid concentrations compared with the amino acid mixture. In the present study, evacuation of the gastric digesta of the MPF group was also found to be delayed compared with the FM and SBM groups as shown in Fig. 4-a. Hilton et al. ${ }^{20)}$ demonstrated that evacuation of 
gastric digesta of rainbow trout fed extruded pellets was prolonged compared with the trout fed on steam pellets. Therefore, physical properties such as hardness of the experimental diets (Table 1) may be partly related to gastric content evacuation in this study, i.e., the evacuation of the gastric digesta in fish fed the MPF diet was slower than those of the FM and SBM diets because of its hardness (Fig. 4-a). However, the hardness of the MPF diet (4.53 $\mathrm{kg} \cdot \mathrm{f}$ ) was similar to the commercial steam pellets of a similar size $(4.15 \mathrm{~kg} \cdot \mathrm{f}$, see Table 1$)$. In addition, we found that the gastric digesta of the MPF groups were homogeneous and contained no pellet-like particles even at 3 hours postfeeding like the other groups. The softer SBM and the harder MPF diets shared a similar pattern of postprandial plasma free amino acid changes irrespective of the hardness of the diets. Accordingly, the hardness of the diets may not be the single cause of the difference in plasma free amino acid changes in this study. More precise examination is necessary to clearly explain the relationship between hardness of diets and postprandial changes of plasma amino acid levels and gastric contents. The similar levels of the gastric nitrogen contents $(\mathrm{mg} / 100 \mathrm{~g} \mathrm{BW})$ of the three groups at 3 hours post-feeding (Fig. 4-a) support that the amounts of the last feed intake were almost the same among treatments.

On the other hand, the insoluble nitrogen contents per gastric digesta (\%) of the SBM and MPF groups remained relatively stable until 21 hours post-feeding, while that of the FM group decreased linearly from 3 to 15 hours (Fig. 4-c). This suggests that the FM proteins were enzymatically digested to a greater extent in the stomach unlike the SBM and MPF proteins, and that the digested soluble FM proteins were transferred into the intestine faster than the other portions of the gastric digesta. In contrast, the SBM and MPF proteins in the gastric digesta might have been transferred into the intestine less digested than the FM proteins. Shimeno et al ${ }^{8)}$ observed similar phenomena in yellowtail between the raw fish and fish meal based moist pellets. They found that the fish meal proteins in the moist pellets were transferred from the stomach into the intestine less digested than the proteins of raw fish. Thus, the inferior chemical digestion of the SBM and MPF proteins to the FM protein in the stomach may be one of the reasons for the difference in the timing of plasma free amino acid peak levels. The higher soluble nitrogen contents of the SBM group than the MPF group at 3 hours post-feeding (Fig. 4-b) might have resulted from digestion of the high amount $0.9 \% \mathrm{NaCl}$ soluble and perchloric acid solution insoluble nitrogen contained in the diet (Table 1).

The digestive process of the test proteins in the intestine is more complicated to understand. Judging from the accumulation of insoluble nitrogen in the intestine (Fig. 5-c) and from the lower soluble nitrogen to total nitrogen ratio of the MPF group than the FM group (Fig. 5-d), the MPF proteins might have been evacuated from the stomach being incompletely digested, and the intestinal digestion of the proteins might have been less active than the FM proteins. This assumption is fairly consistent with the finding of Yamamoto et al. ${ }^{21}$ that the apparent protein digestibility of MPF $(86 \%)$ was lower than that of FM $(94 \%)$ in rainbow trout. Accordingly, the delayed attainment of plasma free amino acid peak levels of the MPF group would have been caused both by the slower evacuation of gastric digesta and by the inferior chemical digestion in the gastrointestinal tract compared with the FM group.

On the other hand, although comparable amounts of the intestinal digesta (\% wet weight / BW) were present in the FM and SBM groups (Fig. 5-a), the nitrogen contents of the SBM group were unexpectedly low (Fig. 5-b). Shimeno et al. ${ }^{9)}$ did not observe such a low nitrogen content in the intestinal digesta of yellowtail force-fed SBM. In addition Yamamoto et al. ${ }^{21)}$ reported that the apparent protein digestibility of SBM (94\%) was as high as FM in rainbow trout. The occurrence of peak levels of the intestinal digesta content at an earlier phase ( 9 hours after feeding, Fig. 5 . a) and the low nitrogen contents in the intestinal digesta (Fig. 5-b, c) of the SBM group, however, seem inconsistent with the delayed attainment of peak levels of plasma free amino acid concentrations. Instead these observations on the digestive process of SBM in the intestine seem consistent with high SBM protein digestibility. ${ }^{21)}$ Although a few non-essential amino acids appeared in high concentrations in the plasma of the three groups (Fig. 3), the total concentrations of non-essential amino acids of the SBM group were considerably lower than the other groups (Fig. 2-c). The reasons for these phenomena observed for the SBM diet group are not clear from the results of the present study. In fish, insulin is known to decrease plasma and tissue free amino acid concentrations, ${ }^{22,23)}$ and also to promote uptake of amino acids into tissue proteins. ${ }^{23}$ Thus, more precise examination into the metabolism of absorbed amino acids is necessary to clarify the relationship between changes in the plasma free amino acid concentrations and digestive process in the gastrointestinal tract of fish fed SBM.

To improve the amino acid balance of fish feed, it is practical and economical to incorporate multiple protein sources at proper ratios. ${ }^{18,19)}$ If the digestive processes of dietary proteins, especially those in the intestine, are different among multiple feed ingredients combined in a diet as we have shown in this study, then the free amino acids liberated from each protein would not be present simultaneously in plasma and cause an imbalance in plasma free amino acid composition. Murai et al ${ }^{4)}$ suggested that simultaneous presentation of balanced amino acids in plasma is important to achieve efficient utilization of the absorbed amino acids. Accordingly, changes in postprandial plasma free amino acid concentrations and digestive processes of dietary proteins in diets containing multiple protein sources should be carefully examined.

In this study we found that plasma free amino acid concentrations of rainbow trout fed diets containing SBM or MPF reached peak levels approximately 9 hours later than the FM diet. This phenomenon for the MPF diet is presumed to be caused by less complete protein digestion and slower evacuation of digesta in the stomach, and less active protein digestion in the intestine. However, the cause of the delay in fish fed the SBM diet is not so clear and more precise examination is needed.

Acknowledgments We wish to thank the staff of the Shiga Prefectural Samegai Trout Farm for providing the experimental fish, and to thank the Kirin Brewery Co. Ltd. for donating MPF. We also thank Mr. A. Akimoto, Nippon Formula Feed Mfg. Co. Ltd., for kindly measuring the hardness of the experimental diets. 


\section{References}

1) O. Deshimaru: Studies on a purified diet for prawn-VIII. Changes in free amino acid contents in muscle, hepatopancreas and blood of prawn after feeding. Nippon Suisan Gakkaishi, 42, 655-660 (1976).

2) S. M. Plakas, T. Katayama, Y. Tanaka, and O. Deshimaru: Changes in the levels of circulating plasma free amino acids of carp (Cyprinus carpio) after feeding a protein and an amino acid diet of similar composition. Aquaculture, 21, 307-322 (1980).

3) S. Yamada, K. L. Simpson, Y. Tanaka, and T. Katayama: Plasma amino acid changes in rainbow trout Salmo gairdneri force-fed casein and a corresponding amino acid mixture. Nippon Suisan Gakkaishi, 47, 1035-1040 (1981).

4) T. Murai, T. Akiyama, H. Ogata, Y. Hirasawa, and T. Nose: Effect of coating amino acids with casein supplemented to gelatin diet on plasma free amino acids of carp. Nippon Suisan Gakkaishi, 48, 703-710 (1982).

5) R. P. Wilson, D. Gatlin III, and W. E. Poe: Postprandial changes in serum amino acids of channel catfish fed diets containing different levels of protein and energy. Aquaculture, 49, 101-110 (1985).

6) T. Murai, H. Ogata, Y. Hirasawa, T. Akiyama, and T. Nose: Portal absorption and hepatic uptake of amino acids in rainbow trout force-fed complete diets containing casein or crystalline amino acids. Nippon Suisan Gakkaishi, 53, 1847-1859 (1987).

7) C. B. Cowey and M. J. Walton: Studies on the uptake of $\left({ }^{14} \mathrm{C}\right) \mathrm{ami}-$ no acids derived from both dietary $\left({ }^{14} \mathrm{C}\right)$ protein and dietary $\left({ }^{14} \mathrm{C}\right)$ amino acids by rainbow trout, Salmo gairdneri Richardson. J. Fish Biol., 33, 293-305 (1988).

8) S. Shimeno, M. Takeda, K. Takii, and T. Ono: Post-feeding changes of digestion and plasma constituent in young yellowtail fed with raw fish and formulated diets. Nippon Suisan Gakkaishi, 59, 507-513 (1993).

9) S. Shimeno, S. Seki, T. Masumoto, and H. Hosokawa: Post-feeding changes in digestion and serum constituent in juvenile yellowtail force-fed with raw and heated defatted soybean meals. Nippon Suisan Gakkaishi, 60, 95-99 (1994).

10) S. Shimeno, T. Mima, T. Masumoto, H. Hosokawa, I. Matsushita, and $\mathrm{K}$. Watanabe: Digestion and post-feeding changes in serum constituents of juvenile yellowtail fed moist pellet diet containing soybean meal. Suisanzoshoku, 43, 185-190 (1995).

11) A. Schuhmacher, C. Wax, and J. M. Gropp: Plasma amino acids in rainbow trout (Oncorhynchus mykiss) fed intact protein or a crystal- line amino acid diet. Aquaculture, 151, 15-28 (1997).

12) T. Murai, T. Akiyama, and T. Nose: Use of crystalline amino acids coated with casein in diets for carp. Nippon Suisan Gakkaishi, 47, 523-527 (1981).

13) M. J. Walton, C. B. Cowey, R. M. Coloso, and J. W. Adron: Dietary requirements of rainbow trout for tryptophan, lysine and arginine determined by growth and biochemical measurements. Fish Physiol. Biochem., 2, 161-169 (1986).

14) T. Murai, H. Ogata, P. Kosutarak, and S. Arai: Effects of methanol treatment and amino acid supplementation on utilization of soy four by chum salmon fingerlings. Bull. Natl. Res. Inst. Aquacult., 12, 37-41 (1987).

15) T. Murai, H. Ogata, A. Villaneda, and T. Watanabe: Utilization of soy flour by fingerling rainbow trout having different body size. Nippon Suisan Gakkaishi, 55, 1067-1073 (1989).

16) C. B. Cowey: Nutrition: estimating requirements of rainbow trout. Aquaculture, 100, 177-189 (1992).

17) T. Yamamoto, P. A. Marcouli, T. Unuma, and T. Akiyama: Utilization of malt protein flour in fingerling rainbow trout diets. Fisheries Sci., 60, 455-460 (1994).

18) T. Akiyama, T. Unuma, T. Yamamoto, P. Marcouli, and S. Kishi: Combinational use of malt protein flour and soybean meal as alternative protein sources of fish meal in fingerling rainbow trout diets. Fisheries Sci., 61, 828-832 (1995).

19) T. Yamamoto, T. Unuma, and T. Akiyama: The effect of combined use of several alternative protein sources in fingerling rainbow trout diets. Fisheries Sci., 61, 915-920 (1995).

20) J. W. Hilton, C. Y. Cho, and S. J. Slinger: Effect of extrusion processing and steam pelleting diets on pellet durability, pellet water absorption, and the physiological response of rainbow trout (Salmo gairdneri R.). Aquaculture, 25, 185-194 (1981).

21) T. Yamamoto, K. Ikeda, T. Unuma, and T. Akiyama: Apparent availabilities of amino acids and minerals from several protein sources in fingerling rainbow trout. Fisheries Sci., 63, 995-1001 (1997).

22) Y. Inui, S. Arai, and M. Yokote: Gluconeogenesis in the eel-VI. Effect of hepatectomy, alloxan, and mammalian insulin on the behavior of plasma amino acids. Nippon Suisan Gakkaishi, 41, 11051111 (1975).

23) T. Murai and H. Ogata: Changes in free amino acid levels in various tissues of common carp in response to insulin injection followed by force-feeding an amino acid diet. J. Nutr., 120, 711-718 (1990). 